\section{CHARACTERISTICS AND ADSORPTION PERFORMANCE OF FORMULATED TRIKOTAC FILTER AIDS}

\author{
N. Masdiana, M. Rashida*, S. Hajara, M. R. Ammarb \\ aAir Resources Research Laboratory, Malaysian Japan International \\ Institute Technology, 54100 UTM Kuala Lumpur, Malaysia \\ bAMR Environmental San. Bhd., Taman Sri Pulai Perdana, 81110 \\ Johor Bahru, Malaysia
}

Article history

Received

11 April 2018

Received in revised form

22 January 2019

Accepted

23 January 2019

Published online

18 April 2019

*Corresponding author rashidyusof.kl@utm.my

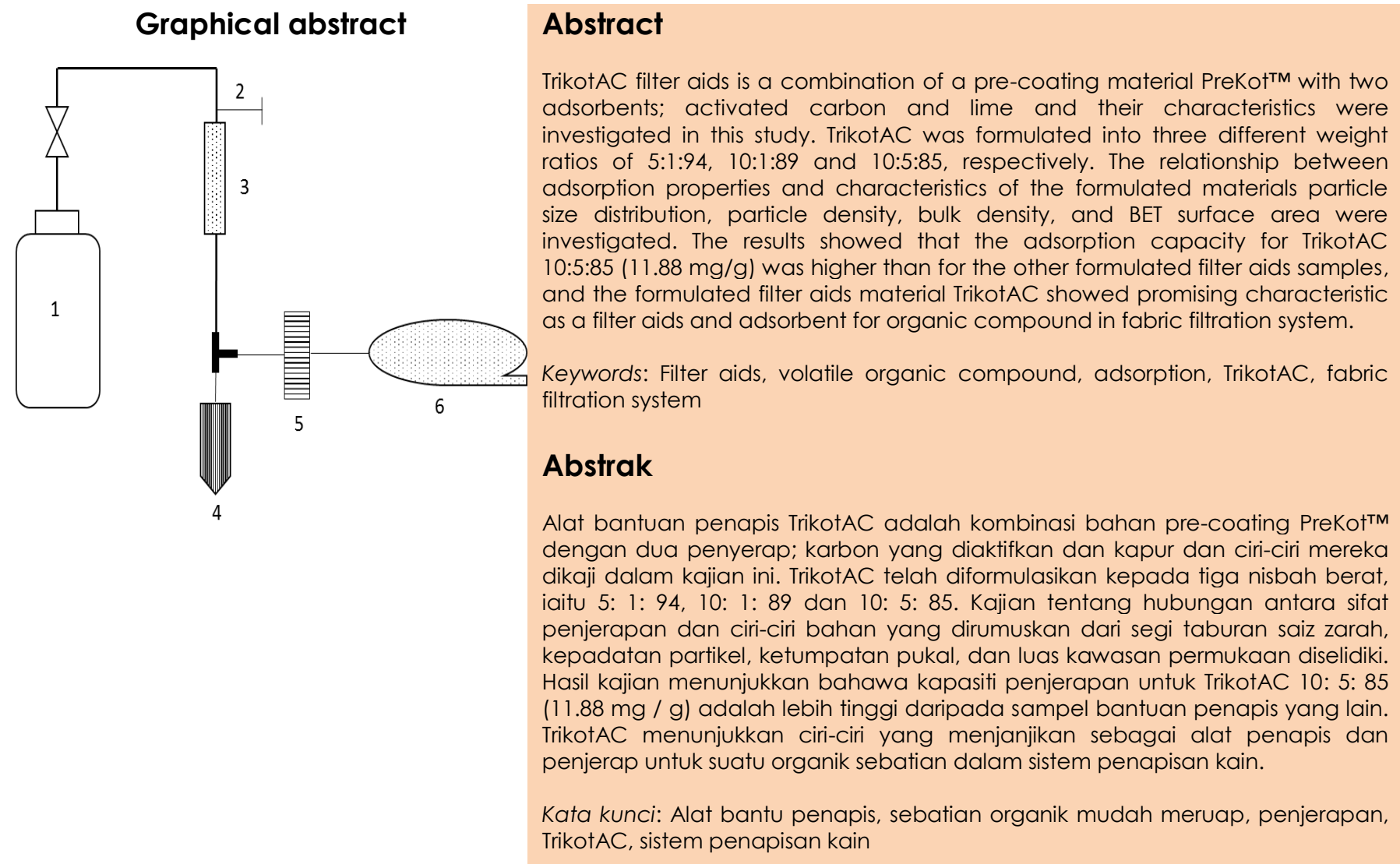

(C) 2019 Penerbit UTM Press. All rights reserved

\subsection{INTRODUCTION}

Environmental issue caused by air pollution remains a major problem in modern societies. For example, emission of air pollution consisting of fine dust or particulate matter, acid gases, heavy metals and volatile organic compounds (VOCs) are emitted into the atmosphere during the operation of municipal solid waste incineration plant (MSWI). In this study, the main focus is on VOCs released where VOCs are 
carbon-based compounds derived from many sources. According to Prada and Fern[1], about $37 \%$ of total VOCs emissions come from coal-fired power plants. Li et al. [2] reported that VOCs has been released from waste incineration. Margarida et al. [3] considered VOCs as one of the main pollutants released during MSWI due to inappropriate burning conditions in the furnace hence increase the VOCs content in the flue gas. The VOCs produced may cover a wide range of compounds, since they can include carbon chains or rings that have a high vapour pressure. Released trace amounts of VOCs can cause severe health effect to humans. Their emissions are now also causing public concern as some VOCs are toxic chemical [4] which can induce eye and throat irritation, cause damage to the liver and central nervous system as well as increase relative rates of leukaemia and lymphoma [5]. Because of these serious effects, Malaysian Clean Air Regulation 2014 has tightened the regulation on VOCs emission from incineration of solid waste to 10 $\mathrm{mg} / \mathrm{Nm}^{3}$ [6]. Therefore, the removal of VOCs is of significant interest to air quality control.

The emission of VOCs from the incineration process is removed by spraying powdered activated carbon into the dirty flue gas stream and collected on fabric filtration system. Apart from being an adsorbent, activated carbon also acts as filter aids in order to overcome the problem of wear and tear in fabric filter [7]. In addition to activated carbon, lime is sprayed separately to adsorb acid gases from the incineration process. The aim of this study is to investigate the physical characteristics and performance of the formulated filter aids which consist of multiple adsorbents of activated carbon, lime and PreKot' ${ }^{\mathrm{TM}}$ (designated as TrikotAC) as flue gas cleaning agent. The effectiveness of the formulated filter aids on VOCs removal in gas streams is presented in this paper.

\subsection{METHODOLOGY}

Three main powder materials used in this study were PreKot'TM, activated carbon and lime and their characteristics are shown in Table 1. Tolvene gas was used as an adsorbate in the adsorption. Tolvene gas with purity of $99 \%$ was specifically made by a commercial gas products company Calgaz, United States. The gas was in standard sized aluminium cylinder of 100 ppm.

Table 1 Specification of raw materials used in the study

\begin{tabular}{|c|c|c|}
\hline $\begin{array}{c}\text { Activated } \\
\text { carbon }\end{array}$ & PreKot ${ }^{T M}$ & Lime \\
\hline $\begin{array}{l}\text { Origin: coconut } \\
\text { Surface area: } \\
1094 \mathrm{~m}^{2} / \mathrm{g}\end{array}$ & $\begin{array}{l}\text { Origin: silica based } \\
\text { Surface area: } \\
2.52 \mathrm{~m}^{2} / \mathrm{g}\end{array}$ & $\begin{array}{l}\text { Origin: } \mathrm{Ca}(\mathrm{OH})_{2} \\
\text { Surface area: } \\
7.58 \mathrm{~m}^{2} / \mathrm{g}\end{array}$ \\
\hline
\end{tabular}

\subsection{Formulation of Filter Aids}

PreKot ${ }^{\mathrm{TM}}$, activated carbon and lime were mixed into 5:1:94, 10:1:89, and 10:5:85 of three different weight percentages, respectively. Prior to starting the formulation, the raw materials were dried in an oven (Memmert, Model UNB 200) for 24 hours at $105^{\circ} \mathrm{C}$. The physical properties of the formulated filter aids designated as TrikotAC were characterised in terms of its particle size distribution, particle density, bulk density, and surface area (BET).

\subsection{Material Characterization}

A particulate sizer (Malvern Mastersizer, 2000) was used to determine the particle size distribution while particle density was measured using gas pycnometer (Micromeritics AccuPyc II 1340), with nitrogen as the carrier gas. The bulk density of the sample was measured based on Equation (1) where the sample was filled and compacted in a pre-weighed $10 \mathrm{~mL}$ standard measuring cylinder up to $10 \mathrm{~mL}$ volume. Then it was re-weighed in order to determine the bulk density [8].

$$
\begin{aligned}
& \text { Bulk density = Wm / Vc } \\
& \text { Where; } \\
& \qquad \begin{array}{ll}
\text { Wm } & =\text { weight of the dried material }(\mathrm{g}) \\
\mathrm{Vc}_{\mathrm{c}} & =\text { volume of the cylinder }(10 \mathrm{~mL})
\end{array}
\end{aligned}
$$

The specific surface area (SBET) was obtained using nitrogen adsorption method by a Micrometrics Tristar II Plus.

\subsection{Adsorption Study}

\section{Sample Preparation}

Prior to mixing, all the raw materials were dried for 24 hours in an oven at $105^{\circ} \mathrm{C}$ to remove all adsorbed gases and moisture content. A fixed glass with an inner diameter of $4 \mathrm{~mm}$, outer diameter of $8 \mathrm{~mm}$, and total length of $60 \mathrm{~mm}$ was used for a dynamic study. The desired amount of adsorbents were filled and compacted into a glass-enclosed with glass wool and covered with a cap. After packaging, all prepared samples were stored in a desiccator prior to use for sampling. 
Adsorption Test

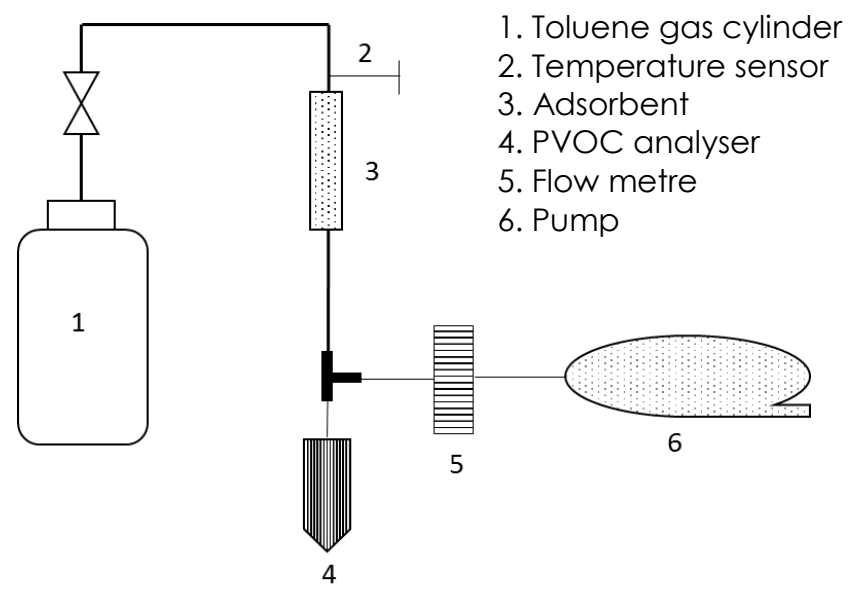

Figure 1 Schematic diagram of the experimental set-up to study VOC adsorption over formulated filter aids

Figure 1 shows the schematic diagram of the adsorption experimental set up which consists of tolvene gas cylinder (100ppm), temperature sensor, adsorbent packed-glass (formulated filter aids), flow rate controller, pump, and PVOC (PpbRAE 3000) analyser. The tolvene gas passed through the system at room temperature $\left(25^{\circ} \mathrm{C}\right)$ towards the adsorbent $(5 \mathrm{mg})$ vertically, and the gas flow rates $(0.45 \mathrm{lpm})$ were controlled by the flow metre. A temperature sensor was used to monitor gas temperature in the system before being adsorbed by the adsorbent. Effluent gas was detected continuously at sampling point using PVOC analyser until the output concentration reached equilibrium point. $\mathrm{PVOC}$ is a real-time monitoring of instrument readings wirelessly with a three-second response time using photoionization detector (PID).

\section{Adsorption Capacity}

It is well known that adsorption capacity can be obtained by using data from adsorption equilibrium. Adsorption equilibrium is the empirical relationship between the concentration of solute on the surface of an adsorbent and the concentration of solute in the gaseous form. Therefore, binary breakthrough curves can be used to calculate the amount of adsorbed solute per adsorbent mass, as shown in Equation 2 [9]:

$$
n_{E q}=Q C_{0} t_{B}-\int_{t_{B}}^{0} Q C(t) d t / M
$$

Where $n_{e q}$ is the adsorption capacity expressed as $\mathrm{mg} / \mathrm{g}, \mathrm{Q}$ is the volumetric flow rate $(\mathrm{L} / \mathrm{min}), \mathrm{C}_{0}$ is the inlet flow concentration $\left(\mathrm{mg} / \mathrm{m}^{3}\right), \quad t_{B}$ is the breakthrough time (minute), $\mathrm{C}(\mathrm{t})$ is the effluent concentration $\left(\mathrm{mg} / \mathrm{m}^{3}\right)$, and $M$ is the weight of adsorbent used (g).

\subsection{RESULTS AND DISCUSSION}

\subsection{Material Characterisation}

Particle Size Distribution

Figure 2 shows a graphical presentation of cumulative weight particle size distribution for all raw materials. It can be clearly seen that lime has the finest particle size distribution compared to other raw materials, whereas for activated carbon, the particle size was moderately distributed and PreKot' ${ }^{\mathrm{TM}}$ consist of coarser particles among the raw materials. For comparison at $50 \%$ cumulative value, the results showed that particle size distribution for PreKot'TM sample was around $138 \mu \mathrm{m}$ while lime and activated carbon contained about $363 \mu \mathrm{m}$ and $46 \mu \mathrm{m}$, respectively. In addition, it was found that lime contained a high number of small particles $(\leq 30 \mu \mathrm{m})$ and a high number of bigger particles (> $200 \mu \mathrm{m}$ ), while the particle size of activated carbon was dominantly $\leq 100 \mu \mathrm{m}$ and particle size of PreKotTM was mostly greater than $200 \mu \mathrm{m}$. The distinctive difference between these three materials for particle size distribution looks ideal for mixing into one component material in this respect.

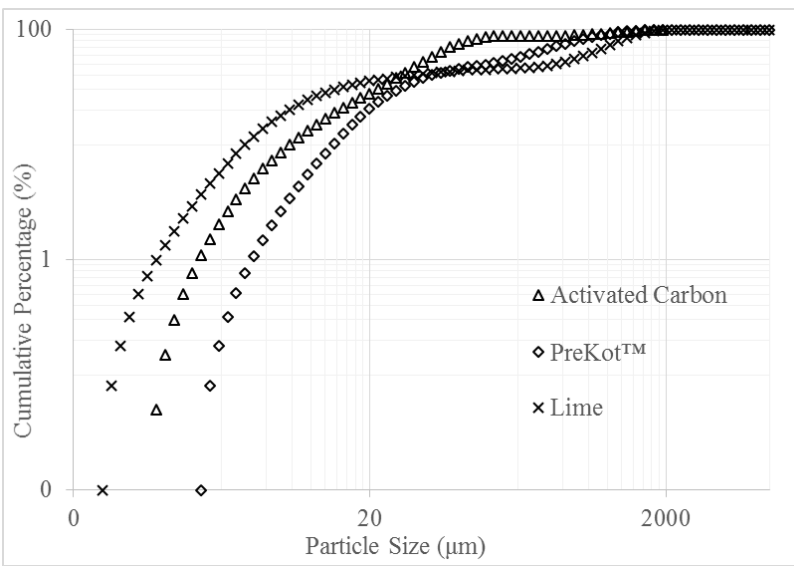

Figure 2 Particle size distribution of PreKot ${ }^{\mathrm{TM}}$, activated carbon and lime

It can be clearly seen in Figure 3 that particle size distribution of TrikotAC laid adequately and consistently between the raw materials. Particle size distribution of the formulated mixture was well distributed compared to raw materials. Thus, it is expected that the mixture would form a porous cake on a filter media, which is a perquisite for a good filter aids property.

The predominantly fine particle size fraction of lime and activated carbon powder presents a high surface area property for better performance in capturing organic related contaminants in dirty flue gas [10]. However, the disadvantage of fine particle size as in the case of lime and activated carbon is that it leads to a high pressure drop build up across 
their filter cake formation. This is due to the difficulty of removing fine particles that have penetrated deep inside the fabric filter the during filtration processes [11]. Therefore, to ensure it is appropriate for use in a real application, a well distributed particle size could be better in order to avoid a high pressure drop during the filtration process as well as adsorb organic contaminant optimally.

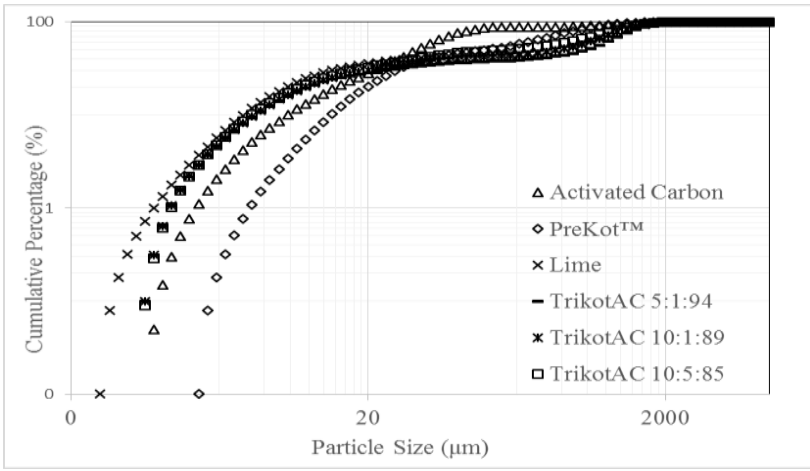

Figure 3 Particle size distribution of raw materials and formulated TrikotAC samples

\section{Bulk Density and Particle Density}

Figure 4 illustrates the results of bulk and particle density of filter aids materials. It was found that, lime had the highest particle and bulk density (2.24 and $0.91 \mathrm{~g} / \mathrm{cm}^{3}$, respectively) followed by activated carbon (1.58 and $0.74 \mathrm{~g} / \mathrm{cm}^{3}$, respectively) and PreKot' ${ }^{\mathrm{TM}}$ (0.77 and $0.30 \mathrm{~g} / \mathrm{cm}^{3}$, respectively). After formulation, the density of TrikotAC samples decreased slightly than the original lime material, but was higher than original materials of activated carbon and PreKot ${ }^{\mathrm{TM}}$. In general, the material density of formulated filter aids decreased in the order of TrikotAC 5:1:94 > 10:5:85 > 10:1:89. The results clearly showed that PreKot'm material plays a role in reducing particle and bulk density, thus enhancing porosity of the material. Applying filter aids material with high porosity helps to reduce pressure drop across the filter cake and is also good for adsorption.

This is because, greater porosity materials lead to better roughness and larger specific surface area [12]. Besides, material density is also important in this case for the purpose of cleaning the fabric filter. Simon et al. [13] reported that there is a high possibility that some detached particle might be redeposited on the filter media during the cleaning process. Leith et al. [14] also reported that most of the dust freed from the filter media during cleaning process, re-deposits rather than falls to the dust hopper. When re-deposition occurs, the dust deposited on the filter media increases causing the pressure drop to rise. Dust agglomerate that possesses higher bulk density would take a shorter time to fall to the dust hopper compared to material with lower bulk density. Hence, in this case, the TrikotAC samples could be the ideal formulated filter aids as their densities lie in the intermediate range between the original materials.

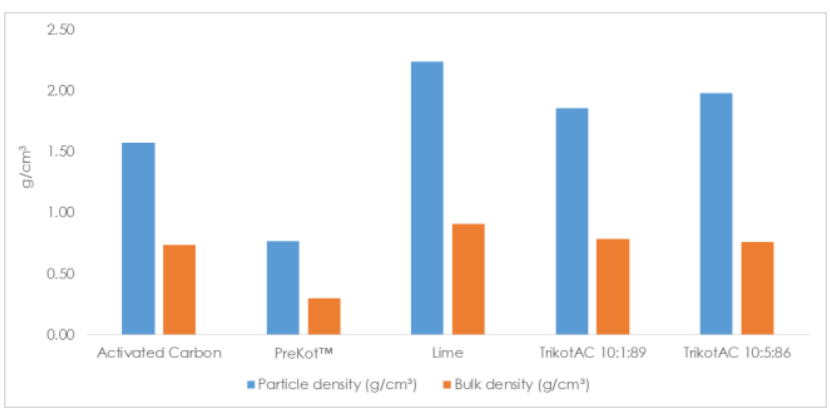

Figure 4 Bulk density and particle density of raw materials and formulated TrikotAC samples

\section{BET Surface Area}

Specific surface area is a fundamental measurement in the field of fine particle characterisation especially in the adsorption process. Specific surface area is defined as the surface area per unit mass of sample [15]. Figure 5 shows the BET surface area of raw materials while Figure 6 shows results of the formulated samples. As can be seen from Figure 5, activated carbon has the largest surface area while PreKot'TM has the smallest surface area with 1094.96 $\mathrm{m}^{2} / \mathrm{g}$ and $2.52 \mathrm{~m}^{2} / \mathrm{g}$, respectively. After mixing, the surface area was larger than the original material of PreKot' ${ }^{\mathrm{TM}}$ and lime, but a far lower than activated carbon, with a rank of activated carbon $>$ TrikotAC 10:5:85 > TrikotAC 5:1:94 > TrikotAC 10:1:89 > lime > PreKot ${ }^{\mathrm{TM}}$.

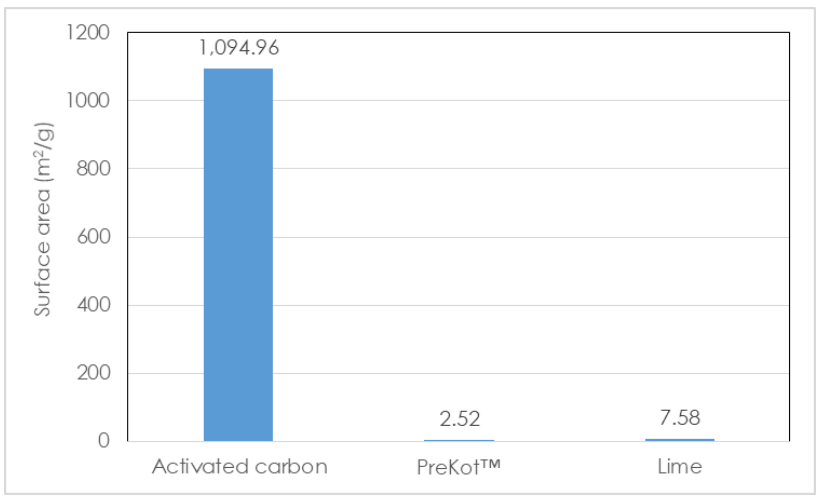

Figure 5 BET surface area of raw materials 


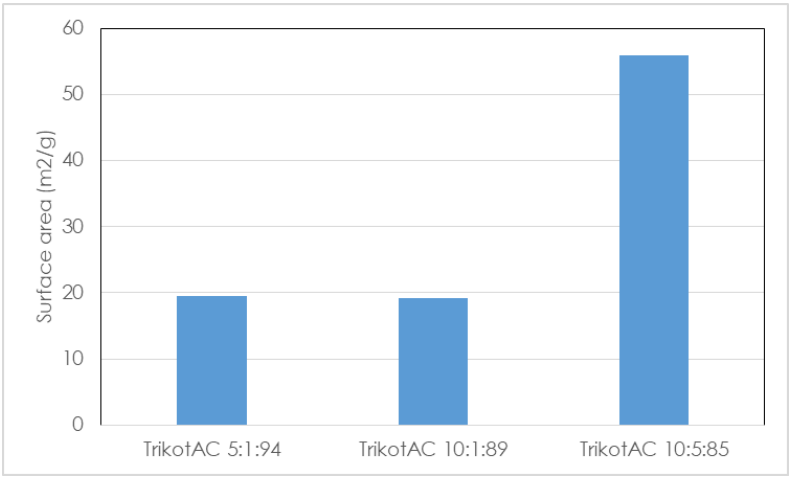

Figure 6 BET surface area of formulated TrikotAC samples

As expected, the decreased amount of activated carbon in the formulation led to a lower surface area. This is due to the fact that activated carbon is a good adsorbent with special characteristics like small particle size, porous structure, and high surface adsorptivity. On the other hand, a large surface area accounts for the highly effective adsorptive characteristics. In this study, although activated carbon alone has a high surface area, it is not suitable to use for real applications as it will produce a compact layer on the surface of the fabric filter, thus increase the pressure drop in the filtration system [6]. Therefore, TrikotAC samples could be a better option to be used in for real applications especially in the adsorption of organic compounds.

\subsection{Adsorption Testing}

\section{Adsorption Breakthrough Curves}

Adsorption capacity and removal efficiency were obtained from breakthrough curves of the adsorption process of tolvene gas for formulated filter aids TrikotAC and compared with the original materials. Figure 7 depicts the breakthrough curves for the adsorption of raw materials and formulated filter aids samples. For raw materials, activated carbon takes the longest time to reach equilibrium point which resulted in the highest adsorption capacity $(115$ $\mathrm{mg} / \mathrm{g}$ ) compared to PreKot' ${ }^{\mathrm{TM}}$ and lime. For formulated filter aids, all samples had their breakthrough start at one minute and have sharp breakthrough curves. This was due to the small number of samples used in this study $(5 \mathrm{mg})$. The real capability of the samples to adsorb tolvene is best described by adsorption capacity of each sample as shown in Table 2. The adsorption capacity for TrikotAC 10:5:85 (11.88 mg/g) was higher than for the other formulated filter aids samples, but it had a significant difference with the original activated carbon material. Basically, using activated carbon alone results in high adsorption capacity as it has a high surface area, but in this case it was not the best option as it can lead to a high pressure drop in the filtration system. Therefore applying TrikotAC samples would be advantageous to reduce the problem due to their characteristics as has been discussed.

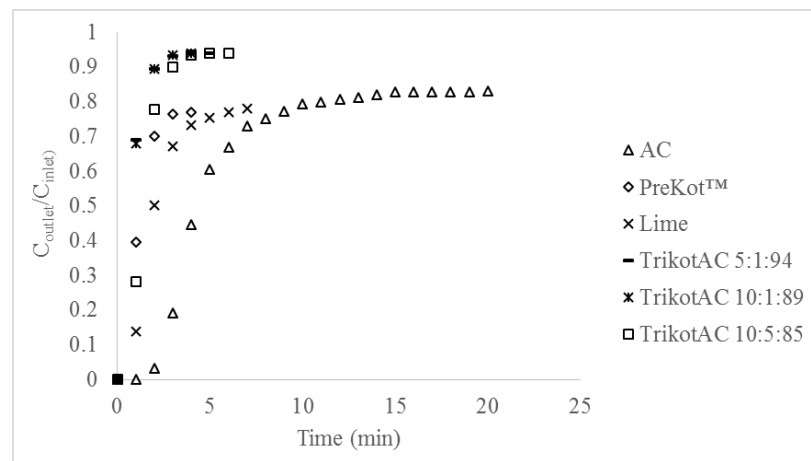

Figure 7 Breakthrough curve for raw materials and formulated filter aids samples

Comparing the amount of tolvene adsorbed at $\mathrm{Ct} / \mathrm{CO}=0.01$, it was found that TrikotAC 10:5:85 had adsorbed $0.27 \mathrm{mg} / \mathrm{Nm}^{3}$ of tolvene while only 0.12 $\mathrm{mg} / \mathrm{Nm}^{3}$ of tolvene was adsorbed by TrikotAC 10:1:89 and TrikotAC 5:1:94, respectively. The results showed that TrikotAC 10:5:85 had better adsorption performance compared to the other samples. In addition, for real applications such as in incineration plants, the adsorbent (formulated filter aids in this case) is injected towards the fabric filter continuously to maintain the adsorption performance for organic compound. The use of TrikotAC 10:5:85 would thus be advantageous as it adsorbs more pollutants for the same exit concentration level. The higher amount of surface area of TrikotAC 10:5:85 among the other formulated samples also explain the higher adsorption capacity of the sample.

Table 2 Adsorption capacity of formulated samples

\begin{tabular}{ccc}
\hline Sample & $\begin{array}{r}\text { Amount of } \\
\text { sample }(\mathbf{m g})\end{array}$ & $\begin{array}{c}\text { Adsorption } \\
\text { capacity }(\mathbf{m g} / \mathbf{g})\end{array}$ \\
\hline TrikotAC 5:1:94 & 5 & 9.90 \\
TrikotAC 10:1:89 & 5 & 7.92 \\
TrikotAC 10:5:85 & 5 & 11.88 \\
\hline
\end{tabular}

\subsection{CONCLUSION}

The formulated filter aids material TrikotAC showed a promising characteristic as a filter aids and adsorbent for organic compounds in fabric filtration system. Having various particle sizes will contribute to better adsorption properties in the flue gas cleaning process. In addition, improvement in terms of particle and bulk density would increase porosity of the material and maintain the adsorption performance of formulated material due to the availability of surface area. It was also found that the combination of activated carbon, PreKot'T and lime led to a reduction in surface area in the formulated material. 
However, the formulated filter aids TrikotAC still have the capability to adsorb tolvene. The results showed that TrikotAC 10:5:85 has the highest adsorption capacity compared to the other samples. In conclusion, formulated filter aids TrikotAC could be applied as a filter aids and adsorbent for volatile organic compound (VOC) during flue gas cleaning process in fabric filtration system.

\section{Acknowledgement}

The authors are grateful to the Ministry of Higher Education (MOHE) for funding this study using TIER 2 grant and also the supervisor and Air Resources, MJIIT team for their appreciable support.

\section{References}

[1] Prada-rodr, D., and Fern, E. 2001. Distribution of Volatile Organic Compounds during the Combustion Process in Coal-Fired Power Stations. Atmospheric Environment. 35: 5823-5831.

[2] Li, G., Zhang, Z., Sun, H., Chen, J., An, T., and Li, B. 2013. Pollution Profiles, Health Risk of Vocs and Biohazards Emitted from Municipal Solid Waste Transfer Station and Elimination by an Integrated Biological-Photocatalytic Flow System: A Pilot-Scale Investigation. Journal of Hazardous Materials. 250-251: 147-154.

[3] Margarida, J. Quina, J. C. M. B., and Rosa, M. Q. 2011. Air Pollution Control in Municipal Solid Waste Incinerators, The Impact of Air Pollution on Health, Economy, Environment and Agricultural Sources. Ed Mohamed, K. K. Croatia InTech. 331-358.

[4] Zaitan, H., Manero, M., Valdés, H., Chimie De,Matière L., Lcmc, C., and Ben, M. 2015. Application of High Silica
Zeolite ZSM-5 in a Hybrid Treatment Process Based on Sequential Adsorption and Ozonation for VOCs Elimination. JES. 1.

[5] Irigaray, P., Newby, J. A. R., Clapp, R., Hardell, L., Howard, V., Montagnier, L., and Belpomme, D. 2007. LifestyleRelated Factors and Environmental Agents Causing Cancer: An Overview. Biomedicine \& Pharmacotherapi. 61: 640-658.

[6] Environmental Quality Act (EQA). 1974. Act 127, Section 22. Part IV, Prohibition and Control of Pollution.

[7] Hajar, S., Rashid, M., Nurnadia, A., and Ammar, M. R. 2015 The Characteristics of a Formulated Filter Aids for Fabric Filters. Powder Technology. 283: 315-320.

[8] Theydan, S. K., and Ahmed, M. J. 2012. Optimization of Preparation Conditions for Activated Carbons from Date Stones Using Response Surface Methodology. Powder Technology. 224: 101-106.

[9] Gironi A., Piemontea V. 2011. Vocs Removal from Dilute Vapour Streams by Adsorption onto Activated Carbon. Chemical Engineering Journal. 172: 671-677.

[10] De Silva, F. 2000. Activated Carbon Filtration. Water Quality Product Magazine. Applied Membrane Inc.

[11] Siti Hajar Binti Abdul Rahim 2015. Formulation of a New Filter Aids Material for Fabric Filtration System. MSc Thesis. Universiti Teknologi Malaysia.

[12] Masdiana, N., Rashid, M., Hajar, S., and Ammar, M. R. 2017. Characteristics of PrekotAC as Formulated Filter Aids and Its Performance to Adsorb Volatile Organic Compound. MATEC Web of Conferences. 111:02002.

[13] Simon, X., Bemer, D., Chazelet, S., Thomas, D., and Regnier, R. 2010. Consequence of High Transitory Airflows Generated By Segmented Pulse-Jet Cleaning of Dust Collector Filter Bags. Powder Technology. 201: 37-48.

[14] Leith, D., Malvin, W., and Feldman, H. 1977. Performance of a Pulse-Jet Filter at High Filtration Velocity, ii. Filter Cake Redeposition. Journal of the Air Pollution Control Association. 27(7): 636-64.

[15] Zhang, X.,Gao, B., Creamer, A. E., Cao, C. And Li, Y. 2017. Adsorption of VOCs onto Engineered Carbon Materials: A Review. Journal of Hazardos Materials. 338: 102-123. 